\title{
Pengaruh Pemberian Terapi Mobilisasi Belt Terhadap Penurunan Nyeri Pada Osteoarthritis (OA) Knee Kronis di RSU 'Aisyiyah Ponorogo
}

\author{
${ }^{1}$ 冈Umar Jamaludin, ${ }^{2}$ Agus Widodo \\ Program Studi Fisioterapi, Fakultas Ilmu Kesehatan, Universitas Muhammadiyah Surakarta \\ Jl. Ahmad Yani, Pabelan, Kartasura, Surakarta- Jawa Tengah 57162 \\ Email: umarjamaludin592@gmail.com
}

Tanggal Submisi: 16 Desember 2020; Tanggal Penerimaan: 29 Desember 2020

\begin{abstract}
ABSTRAK
Latar Belakang: Osteoarthritis (OA) adalah ketika sendi mengalami pengikisan kartilago dan mempengaruhi tulang di bawahnya sehingga menyebabkan pembentukan osteofit atau tulang baru di antara perbatasan sendi. Salah satu permasalahan yang biasanya timbul karena OA adalah nyeri. Nyeri akan terasa hilang muncul di fase-fase akut, dan pada fase kronis akan menjadi konstan selama berbulan-bulan atau bertahun-tahun.

Tujuan Penelitian: Untuk mengetahui pengaruh pemberian terapi mobilisasi belt dalam menurunkan nyeri pada Osteoarthritis (OA) knee kronis.

Metode Penelitian: Penelitian ini menggunakan metode quasy eksperimental dengan desain penelitian randomized control pre test-post test design. Subjek penelitian ini berjumlah 30 pasien yang merupakan pasien rawat jalan dengan diagnosa Osteoarthritis (OA) knee kronis dan terbagi menjadi 2 kelompok yaitu kelompok perlakuan dengan jumlah 15 pasien dan kelompok kontrol dengan jumlah 15 pasien. Infrared Rays (IR) dan TENS diberikan kepada kelompok kontrol, sedangkan kelompok perlakukan diberikan IR, TENS dan ditambahkan terapi mobilisasi belt dengan frekuensi latihan sebanyak 3 kali dalam seminggu selama 4 minggu.

Hasil Penelitian: Pengukuran nyeri dengan menggunakan Numeric Rating Scale (NRS) menunjukkan terjadinya penurunan skala nyeri antara pre-test dan post-test pada kelompok perlakuan.

Kesimpulan: Terapi mobilisasi dengan menggunakan belt memberikan pengaruh penurunan nyeri pada pasien Osteoarthritis (OA) knee kronis.

Kata kunci: osteoarthritis, nyeri, numeric rating scale, terapi mobilisasi belt.
\end{abstract}

\section{ABSTRACT}

Background: Osteoarthritis (OA) is a compilation of joints that experience the erosion of cartilage and the bone below that causes osteophytes or new bone between the joints. One of its problem is pain. Pain will appear in the acute phase, and in the chronic phase will be constant for months or years.

Objective: To determine the effect of the belt mobilization therapy in reducing pain in chronic knee osteoarthritis (OA).

Research Methods: This study used a quasy experimental method with a randomized controlled pretest post-test design. The subjects of this study were 30 patients who were diagnosed chronic knee osteoarthritis (OA) and were divided into 2 groups: treatment group consisting of 15 patients and control group with a total of 15 patients. Infrared Rays (IR) and TENS were given to the control group, while the treatment group was given IR, TENS and belt mobilization therapy; with exercise frequency 3 times in 4 weeks.

Results: Measurement of pain using the Numeric Rating Scale (NRS) which showed a decrease in pain scale between pre-test and post-test in the treatment group.

Conclusion: Belt mobilization therapy provides a reduction in pain in chronic knee Osteoarthritis (OA) patients.

Keywords: osteoarthritis, pain, numerical rating scale, belt mobilization therapy. 


\section{PENDAHULUAN}

Osteoarthritis (OA) dikenal sebagai penyakit sendi kronis degeneratif, yang merupakan penyakit arthritis yang paling umum, yaitu ketika sendi mengalami pengikisan kartilago dan mempengaruhi tulang di bawahnya sehingga menyebabkan pembentukan osteofit atau tulang baru di antara perbatasan sendi (Fransen et al., 2015).

Menurut WHO prevalensi OA di seluruh dunia pada pria adalah 9,6\% dan pada wanita berusia di atas 60 tahun lebih banyak yaitu $18 \%$. Di Indonesia, prevalensi OA pada usia 61 tahun sebanyak 5\%. Prevalensi OA lutut masih cukup tinggi yaitu sebesar $15,5 \%$ pada pria dan $12,7 \%$ pada wanita dari total populasi Indonesia yang berjumlah 255 juta orang (Ahmad et al., 2018). OA lutut menempati urutan ketiga kasus yang banyak ditangani di RSU 'Aisyiyah Ponorogo.

Keluhan utama seseorang yang menderita OA knee kronis adalah nyeri, kekakuan sendi dan otot, ketidakstabilan dan penurunan fungsi sendi. Nyeri adalah gejala paling awal. Namun, nyeri ini akan terasa hilang muncul di fase-fase akut, dan pada fase kronis akan menjadi konstan selama berbulan-bulan atau bertahun-tahun (Kulkarni dan Kamat, 2017).

Metode konservatif yang banyak diberikan fisioterapi pada pasien OA knee kronis agar dapat menurunkan nyeri, memperlambat kelemahan otot, kekakuan sendi, mencegah atrofi otot serta mengurangi keterbatasan gerak sendi lutut berupa elektroterapi (Infrared Rays (IR), Electrical Stimulation (TENS, Interferential), Ultrasound (US), dan lain-lain), hidroterapi, manual terapi (manipulasi, mobilisasi, dan massage) (Silva et al., 2015). Penanganan operatif dapat dilakukan dilihat berdasarkan gejala yang dirasakan pasien (misal, nyeri dan fungsi lutut), grade OA dan faktor yang berhubungan dengan pasien (usia, tingkat aktivitas fisik) (Ronn et al., 2011).

Dalam penelitian ini, peneliti memberikan terapi mobilisasi belt yang bertujuan untuk mengembalikan gerakan fungsional tanpa rasa sakit dan keterbatasan gerakan. Peneliti memilih terapi mobilisasi belt dalam penelitiannya, karena di RSU 'Aisyiyah Ponorogo para pasien yang diberikan teknik mobilisasi ini banyak mengalami penurunan nyeri pada kasus muskuloskeletal terutama kasus OA nyeri lutut kronis. Sehingga dapat disimpulkan tujuan dalam penelitian ini adalah untuk mengetahui pengaruh terapi mobilisasi belt dalam menurunkan nyeri OA knee kronis dan untuk menganalisa penurunan derajat nyeri yang terjadi pada kelompok dengan terapi mobilisasi belt dan kelompok dengan Infrared Rays (IR) dan TENS.

\section{METODE PENELITIAN}

Penelitian ini menggunakan metode quasy eksperimental dengan desain penelitian randomized control pre test-post test design yang bertujuan untuk mengetahui pengaruh pemberian terapi mobilisasi belt terhadap penurunan nyeri pada pasien OA knee kronis di RSU 'Aisyiyah Ponorogo.

Subjek pada penelitian ini berjumlah 30 pasien yang merupakan pasien rawat jalan dengan diagnosa OA knee kronis yang memenuhi kriteria inklusi dan eksklusi. Kriteria inklusi dalam penelitian ini yaitu: a) Pasien dengan diagnosa OA knee kronis di RSU 'Aisyiyah Ponorogo, b) Pasien dengan hasil pemeriksaan nyeri Numerical Rating Scale (NRS); severe pain, yaitu antara nilai 7-9, c) OA knee grade 1-3 (sesuai klasifikasi Kellgren dan Lawrence), d) Laki-laki/ wanita dengan usia 50 tahun ke atas, e)Pasien dengan IMT lebih dari $25,0 \mathrm{~kg} / \mathrm{m}^{2}$, f) Nyeri lutut yang dirasakan lebih dari 3 bulan, g) Pasien bersedia menjadi responden penelitian. Sedangkan kriteria eksklusinya, yaitu: a) Pasien yang mengkonsumsi 
obat penghilang rasa nyeri/ analgetik, b) Pasien punya riwayat cedera ekstremitas bawah dalam kurun waktu 3 bulan, c) Adanya post fracture pada pelvis, hip, lutut, dan riwayat knee reconstrucive surgery, d) Adanya luka bakar pada ekstremitas bawah e) Adanya deformitas sendi lutut.

Subjek ini terbagi menjadi 2 kelompok yaitu masing-masing kelompok berjumlah 15 pasien, kelompok perlakuan diberikan IR, TENS dan ditambahkan terapi mobilisasi belt dan kelompok kontrol diberikan Infrared Rays (IR) dan TENS saja. Frekuensi latihan sebanyak 3 kali dalam seminggu selama 4 minggu pada bulan November-Desember 2019.

Prosedur pelaksanaan terapi mobilisasi belt adalah sebagai berikut: 1)Mobilisasi Medial Gliding: Posisi pasien supine lying. Palmar tangan kanan terapis diletakkan di bawah lutut (distal lutut) dan tangan kiri diletakkan di atas paha (proksimal lutut). Kemudian, terapis melakukan medial gliding pada lutut dan meminta pasien untuk melakukan fleksi dan ekstensi lutut mempertahankan medial gliding sepanjang range of motion, 2) Mobilisasi Lateral Gliding: Pasien supine lying. Palmar tangan kanan terapis diletakkan di bawah (distal tungkai) dan tangan kiri diletakkan di atas dari lutut (proksimal dari lutut). Kemudian, terapis melakukan lateral gliding pada lutut dan meminta pasien untuk melakukan fleksi dan ekstensi lutut mempertahankan lateral gliding sepanjang range of motion. Setiap gerakan tersebut pada hari pertama diberikan sebanyak 2 set, 10 kali pengulangan, pada hari kedua dan seterusnya diberikan sebanyak 4 set, 10 kali pengulangan (Ughreja dan Shukla, 2017).

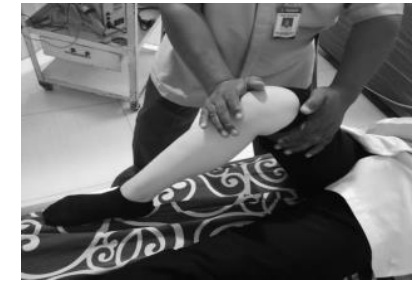

Tabel 1. Mobilisasi Medial Gliding

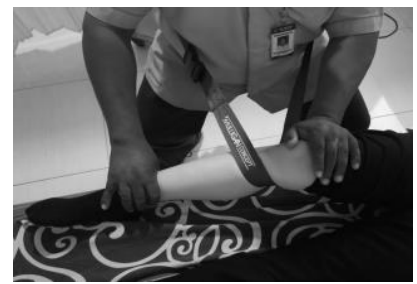

Tabel 2. Mobilisasi Lateral Gliding

Pengukuran skala nyeri diukur menggunakan Numeric Rating Scale (NRS) yang merupakan salah satu instrumen pengukuran untuk melihat tingkat nyeri yang dirasakan pasien.

Teknik analisa data yang dilakukan dalam penelitian ini, yaitu: uji normalitas data menggunakan uji Saphiro Wilk, uji ini dipilih karena responden $<50$, untuk uji pengaruh menggunakan Wilcoxon test dan uji beda pengaruh menggunakan uji Mann Whitney Test, kedua teknik analisa data dipilih karena hasil normalitas data yang tidak berdistribusi normal $\mathrm{p}<0,05$.

\section{HASIL}

Pada Tabel 1 menunjukkan bahwa kelompok perlakuan dengan total responden 15 orang, jumlah jenis kelamin perempuan lebih banyak, yaitu 12 orang. Pada karakteristik usia didapatkan rentang usia 50-72 tahun. Karakteristik IMT, 10 orang masuk dalam kategori Obese 1 (IMT 25,00$29,9 \mathrm{~kg} / \mathrm{m}^{2}$ ) dan 5 orang masuk dalam kategori Obese 2 (IMT $>30,0 \mathrm{~kg} / \mathrm{m}^{2}$ ). Karakteristik nyeri pre-test skala nyeri minimal 7 , dan skala nyeri maksimal 9. 
Tabel 3. Karakteristik Responden

\begin{tabular}{llllll}
\hline $\begin{array}{l}\text { Karak- } \\
\text { teristik }\end{array}$ & \multicolumn{2}{l}{ K.Perlakuan } & K.Kontrol & $\begin{array}{l}\mathrm{p} \text { - } \\
\text { value }\end{array}$ \\
\cline { 2 - 5 } & $\mathrm{n}=15$ & $\%$ & $\mathrm{n}=15$ & $\%$ & \\
\hline Gender & & & & & 0,426 \\
Lk-lk & 3 & $20 \%$ & 5 & $33,3 \%$ & \\
Wnt & 12 & $80 \%$ & 10 & $66,7 \%$ & \\
\hline Age & & & & & 0,314 \\
Mean \pm & 60,87 & & $63,93 \pm$ & \\
SD & $\pm 7,308$ & & 8,988 & & \\
Min & 50 & & 51 & & \\
Max & 72 & & 78 & & 0,426 \\
\hline IMT & & & & & \\
Obese 1 & 10 & $66,7 \%$ & 12 & $80 \%$ & \\
Obese 2 & 5 & $33,3 \%$ & 3 & $20 \%$ & \\
\hline Nyeri pre & & & & & \\
Mean \pm & $8,00 \pm$ & & $7,73 \pm$ & & \\
SD & 0,926 & & 0,884 & & \\
Min & 7 & & 7 & & \\
Max & 9 & & 9 & & \\
\hline
\end{tabular}

Pada kelompok kontrol dengan total responden 15 orang, jumlah jenis kelamin perempuan lebih banyak, yaitu 10 orang dan responden laki-laki 5 orang. Pada karakteristik usia didapatkan rentang usia 51-78 tahun. Karakteristik IMT 12 orang masuk dalam kategori Obese 1 (IMT 25,00-29,9 kg/m ${ }^{2}$ ) dan 3 orang masuk dalam kategori Obese 2 (IMT>30,00 $\mathrm{kg} / \mathrm{m}^{2}$ ). Karakteristik nyeri pre-test skala nyeri minimal 7, dan skala nyeri maksimal 9.

Uji normalitas dengan Saphiro Wilk pada Tabel 2 didapatkan hasil pada kelompok kontrol p-value nyeri pre-test 0,001 , sedangkan p-value post-test 0,048 . Pada kelompok perlakuan $\mathrm{p}$-value nyeri pre-test 0,001 , dan post-test 0,003 . Maka dapat ditarik kesimpulan bahwa semua data berdistribusi tidak normal karena semua nilai $\mathrm{p}$ value $<0,05$.

Tabel 2. Uji Normalitas

\begin{tabular}{lll}
\hline $\begin{array}{l}\text { Selisih pre-test, } \\
\text { post test }\end{array}$ & p-value & Kesimpulan \\
\hline Skala Nyeri & 0,000 & $\mathrm{H}_{1}$ diterima \\
\hline
\end{tabular}

Suatu data dikatakan berdistribusi homogen jika Sig $>0,05$, dapat diamati pada Tabel 3 di bawah ini, jenis kelamin, usia, IMT dan nilai nyeri pretest menunjukkan bahwa data-data tersebut Sig>0,05 sehingga dapat dikatakan semua data homogen.

Tabel 3. Uji Homogenitas

\begin{tabular}{lll}
\hline Karakteristik & Sig & Karakteristik \\
\hline Jenis Kelamin & 0,116 & Homogen \\
Usia & 0,647 & Homogen \\
IMT & 0,116 & Homogen \\
Nilai nyeri pre & 0,900 & Homogen \\
\hline
\end{tabular}

Apabila hasil dari suatu data $\mathrm{p}<0,05$ maka $\mathrm{H}_{0}$ ditolak dan $\mathrm{H}_{1}$ diterima dan jika $\mathrm{p}>0,05$ maka $\mathrm{H}_{0}$ diterima dan $\mathrm{H}_{1}$ ditolak. Berdasarkan hasil pada Tabel 4 dapat diketahui uji pengaruh pada kelompok perlakuan diperoleh p-value 0,001 dimana $\mathrm{p}<0,05$ maka $\mathrm{H}_{1}$ diterima, sehingga dapat ditarik kesimpulan bahwa terdapat pengaruh penambahan terapi mobilisasi belt terhadap penurunan nyeri pada pasien OA knee kronis.

Tabel 4. Uji Pengaruh Kelompok Penelitian

\begin{tabular}{lllll}
\hline Kelompok & $\mathrm{N}$ & $\mathrm{Z}$ & $\begin{array}{l}\mathrm{p} \text { - } \\
\text { value }\end{array}$ & Kesimpulan \\
\hline K. Kontrol & 15 & $-3,571$ & 0,000 & $\mathrm{H}_{1}$ diterima \\
K. Perlakuan & 15 & $-3,443$ & 0,001 & $\mathrm{H}_{1}$ diterima \\
\hline
\end{tabular}

Berdasarkan hasil uji beda pengaruh Mann Whitney pada Tabel 5 di bawah ini, dapat diketahui uji beda pengaruh terhadap penurunan nyeri pada kelompok perlakuan dan kelompok kontrol diperoleh p-value 0,000 maka $\mathrm{H}_{1}$ diterima, sehingga dapat ditarik kesimpulan bahwa terdapat perbedaan pengaruh antara kelompok perlakuan dan kelompok kontrol.

Tabel 4. Uji Beda Pengaruh

\begin{tabular}{lll}
\hline $\begin{array}{l}\text { Selisih pre-test, } \\
\text { post test }\end{array}$ & $\mathrm{p}$-value & Kesimpulan \\
\hline Skala Nyeri & 0,000 & $\mathrm{H}_{1}$ diterima \\
\hline
\end{tabular}




\section{PEMBAHASAN}

Mekanisme penurunan nyeri dalam teknik manual terapi dikategorikan dalam 2 jalur: jalur mekanisme biomekanik dan jalur neurofisiologi. Mekanisme biomekanik dalam konteks mobilisasi dengan menggunakan belt akan berfokus pada koreksi kesalahan posisi (position fault) dengan menggunakan treatment berupa glide. Aplikasi teknik mobilisasi ini akan membantu dalam mengembalikan kinematik normal dari OA lutut yang juga akan menyebabkan penurunan nyeri.

Abnormal Axis of Rotation (rotasi sendi yang abnormal) atau dikenal sebagai positional fault mengacu pada gerakan arthrokinematic (translasi dan rotasi) yang terjadi antara permukaan sendi dalam hubungannya satu sama lain ketika tulang bergerak. Abnormal Axis of Rotation jarang diperhatikan yang akan berakibat pada perubahan fisiologis pada sendi sehingga akan menyebabkan muscle spasm, muscle imbalance dan kekakuan sendi artikular atau periartikular. Perubahan fisiologis ini akan merangsang stimulasi afferent yang abnormal dari mechanoreceptor ke sistem neuromuskuler, sehingga akan mengarah pada kegagalan dalam stabilisasi sendi, yang akan memunculkan stress pada jaringan lebih lanjut. Maka dari itu dengan penerapan teknik mobilisasi dengan menggunakan belt, gerakan abnormal ini dapat dinormalisasi sehingga gerakan arthrokinematic akan mengikuti fungsi fisiologisnya (Baeske, 2016).

Perubahan biomekanik lokal akibat gerakan glide akan mengubah aktivitas mechanoreceptor lokal dengan menghasilkan perbaikan pada artrokinematika sendinya. Sebagai akibatnya, penurunan aktivitas reseptor tipe III dan IV (nosiseptor) dan peningkatan aktivitas tipe I dan II dapat terjadi. Dengan demikian, jika teknik ini berhasil, gerakan yang menimbulkan nyeri karena aktivasi nociceptive yang tidak diinginkan akan bebas dari rasa sakit karena perubahan dalam aktivitas mechanoreceptor sebagai hasil dari input biomekanik dari gerakan mobilisasi. Setelah itu, variasi dalam arah glide yang dilakukan akan menimbulkan distribusi beban yang berbeda pada jaringan artikular dan periartikular, yang akan mengubah aktivitas mechanoreceptor dengan menghambat kerja nosiseptor (tipe III dan IV) sehingga memfasilitasi aktivitas tipe I dan II, yang mengarah pada peningkatan range of motion bebas rasa sakit.

Sedangkan, dalam mekanisme neurofisiologisnya terjadi proses sistem penghambatan dan penurunan nyeri, dan mekanisme proses perubahan nyeri central (Bhagat et al., 2019). Gerakan pada mobilisasi ini akan menghasilkan efek neurofisiologis dengan menghasilkan zat analgesia.

Akibatnya, ketika seorang terapis menerapkan gliding ke segmen tertentu dan gerakan itu digerakkan tanpa rasa sakit, seseorang akan menyimpulkan bahwa input biomekanik yang dihasilkan oleh terapis mengubah artrokinematik lokal, sehingga distribusi beban pada jaringan yang rusak memberikan input afferent baru ke SSP (dengan merangsang mechanoreceptor tipe I dan II) atau mengurangi pengaruh pergerakan pada nosiseptor (tipe III dan IV). Perubahan biomekanik pada sendi ini tidak serta-merta menyiratkan bahwa ia menunjukkan gerakan yang lebih baik dengan mengubah gerakan artrokinematik yang terjadi pada sendi, ini hanya berarti bahwa gliding mengubah aktivitas mechanoreceptor lokal yang bertanggung jawab atas nociception selama gerakan. Jadi, alih-alih positional fault terdapat pada sendi, akan langsung dikoreksi oleh gerakan gliding pada mobilisasi tersebut, input biomekanik baru akan mengubah distribusi beban pada jaringan sehingga abnormalitas aktivitas mechanoreceptor diperbaiki.

Aspek menarik ditemukan dalam beberapa studi klinis yang menunjukkan bahwa manfaat teknik mobilisasi dapat dicapai hanya ketika 'gliding' tercapai atau tepat. Fakta ini 
menunjukkan pentingnya aspek-aspek spesifik dari teknik seperti force, arah gerakan, contact point dan gerakan pengulangan untuk mendapatkan hasil yang diinginkan. Oleh karena itu, aspek biomekanik dikombinasikan dengan neurofisiologi artikular dan periartikular yang sangat penting dalam prosedur mobilisasi dengan menggunakan belt ini (Baeske, 2016).

\section{KESIMPULAN DAN SARAN}

Dari hasil analisis data penelitian dan pembahasan yang telah dilakukan dapat disimpulkan bahwa terdapat pengaruh pemberian terapi mobilisasi dengan menggunakan belt terhadap penurunan nyeri pada pasien OA kronis pada sendi lutut di RSU 'Aisyiyah Ponorogo. Berdasarkan kesimpulan tersebut, penelitian ini berimplikasi bahwa terapi mobilisasi belt memberikan pengaruh terhadap penurunan nyeri berdasarkan pengukuran skala nyeri dengan menggunakan NRS sehingga penambahan metode latihan ini dapat menjadi solusi dalam menurunkan nyeri pada kondisi OA kronis sendi lutut.

Peneliti juga memberikan saran kepada para fisioterapis agar dapat menerapkan pemberian terapi mobilisasi dengan menggunakan belt untuk menurunkan tingkat nyeri pada pasien OA sendi lutut kronis dan untuk para peneliti selanjutnya agar dapat mengembangkan penelitian ini dengan melakukan penelitian efektifitas terapi mobilisasi dengan belt dalam mengatasi jenis penyakit sendi lainnya, dan mengembangkan penelitian pada tingkat populasi yang lebih beragam (jumlah, usia, dll).

\section{UCAPAN TERIMA KASIH}

Terima kasih disampaikan kepada Bapak Agus Widodo yang telah membantu proses pembuatan penelitian ini dan kepada seluruh subjek penelitian RSU ‘Aisyah Ponorogo.

\section{DAFTAR PUSTAKA}

Ahmad IW, Rahmawati LD, Wardhana TH. 2018. Demographic Profile, Clinical and Analysis of Osteoarthritis Patients in Surabaya. Biomolecular and Health Science Journal.

Arya RK, Jain V. 2013. Osteoarthritis of the Knee Joint: An Overview. Vol. 14, No.2.Journal, Indian Academy of Clinical Medicine.

Ayanniyi O, Egwu RF, Adeniyi AF. 2017.

Physiotherapy Management of Knee Osteoarthritis in Nigeria-A Survey of SelfReported Treatment Preference. Hong Kong Physiotherapy Journal.

Baeske, Rafael. 2016. Mobilization With Movement: A Step Towards Understanding The Importance of Peripheral Mechanoreceptors, Physical Therapy Reviews

Bhagat M, Neelapala YVR, Gangavelli R. 2019.

Immediate Effects of Mulligan's Techniques on Pain and Functional Mobility in Individuals With Knee Osteoarthritis: A Randomized Control Trial. Physiother Res Int.

Bisa, Maksimus. 2018. Intervensi Mulligan Mobilization with Movement Lebih Baik Dari Semisquat Exercise Dalam Meningkatkan Fungsional Sendi Lutut Pada Kasus Chondromalacia Patella. JDP Vol. 11, No.3: 270-306.

Breivik H, Borchgrevink PC, Allen M, Rosseland LA, Romundstad L, Hals EKB, Kvarstein G, Stubhaug A. 2008. Assessment of Pain. British Journal of Anaesthesia 101 (1): 1724.

DeAvilla, Nicole. 2013. Keeping on Track with Knee.https://www.expandinglight.org/blog/ yoga/yoga-therapist-training/keeping-ontrack-with-knees/ diakses pada 1 Oktober 2019.

Fransen, McConnell S, Harmer AR, Van der Esch M, Simic M, Bennell KL. 2015. Exercise 
for Osteoarthritis of the Knee (Review). The Cochrane Collaboration. John Wiley\&Sons, Ltd.

Hame SL, Alexander RA. 2013. Knee Osteoarthritis in Women. Curr Rev Musculoskelet Med 6:183-187.

Kisner C, Colby LA. 2012. Therapeutic Exercise Foundations and Techniques Sixth Edition, Philadelphia: F.A, Davis Company.

Kulkarni AV, Kamat MM. 2017. A Study to Determine the Effectiveness of Mobilization with Movement Techniques in Knee Osteoarthritis Pain, Vol. 7; Issue: 4. International Journal of Health Science and Research.

Lespasio MJ, Piuzzi NS, Husni ME, Muschler GF, Guarino AJ, Mont MA. 2017. Knee Osteoarthritis: A Primer. The Permanente Journal.

Litwic A, Edwards MH, Dennison EM, Cooper C. 2013. Epidemiology and Burden of Osteoarthritis.British Medical Bulletin.Oxford University Press.

Loeser, Richard F. 2017. The Role of Aging in The Development of Osteoarthritis. Transaction of The American Clinical and Climatological Association, Vol. 128.

Meyler, Zinovy. 2018. Knee anatomy. Arthritis Health. https://www.arthritis-health.com/ author/zinovy-meyler-do diakses pada 1 Oktober 2019.
Mora JC, Przkora R, Almeida YC. 2018. Knee Osteoarthritis: Pathophysiology and Current Treatmenr Modalities. Journal of Pain Research: 11 2189-2196.

Pathak A, Sharma S, Jensen M. 2018.The Utility and Validity of Pain Intensity Rating Scales for Use in Developing Countries. Pain Around the World.

Ronn K, Reischi N, Gautier E, Jacobi M. Current Surgical Treatment of Knee Osteoarthritis. Hindawi Publishing Corporation Arthritis, Vol 2011.

Silva A, Mello MT, Junior SA, Queiroz SS, Tufik S, Mattiello SM. 2015. Therapeutic Modalities and Postural Balance of Patients with Knee Osteoarthritis: Systematic Review. Fisioter, Mov.

Ughreja RA, Shukla YU. 2017. Mulligan's Mobilisation with Movement (MWM) Relieves Pain and Improves Functional Status in Osteoarthritis Knee.International Journal Physiotherapy. Vol 4(2), 132-138.

Vicenzino B, Paungmali A, Teys P. 2011. Mulligan's Mobilization-With-Movement, Positional Faults and Pain Relief: Current Concepts From a Critical Review of Literature. Manual Therapy 12, Science Direct. 